\title{
THE SPECTRUM OF U.S. 40
}

\section{WALDO R. TOBLER, University of Michigan}

Geographical central place theory (5) clearly suggests the possible existence of, or tendency toward, a two-dimensional repetitiousness in the distribution of cities throughout the landscape. Spectral analysis (4) (3) would appear to offer a natural approach to the examination of such an hypothesis. As a preliminary to a more detailed analysis, the distribution of populated places along U.S. Highway 40 from Baltimore to San Francisco has been examined.

Probably even the casual traveller observes a certain repetition along a highway; several small towns are followed by a larger town and so on. Central place theory, after invocation of assumptions regarding the homogeneity of the space, suggests an exact periodicity. This can be characterized in several ways (7), only one of which is described here. Let $A, B, C, D, \ldots$ be a set of towns of increasing size. An expected sequence of equally spaced towns is then

DAABAABAACAABAABAACAABAABAACAABAABAAD.

In the frequency domain this might be interpreted as a line spectrum. The simplifying assumptions of the theory, like the physicists in vacuo, cannot ever be met, nor are the data perfect, so that a spectral density calculation would appear more appropriate. The conventional analysis assumes that the signal to be analyzed is continuous, though perhaps discretely sampled; for exceptions see (2). The data at hand effectively give only the existence or nonexistence of a town plus the population of the town, Figure 1.

More specifically, using a routing and maps of Highway 40 supplied by the American Automobile Association, a record was prepared of all towns within one mile of the route and included the distance (to the nearest mile) of the towns from central Baltimore. The older highway was preferred when a choice existed with respect to an expressway. Bureau of the Census statistics yielded the 1960 population of each town. Geographical theory and the exploratory nature of the study suggested that it would be desirable to create a continuous population density signal from the raw data. The data could, of course, be analyzed from many alternate points of view.

The raw data consists of population "spikes." From previous work (12), it is known that the area of a town in the United States can be estimated with considerable accuracy $\left(r^{2}=.85, N=213\right)$ from the empirical relation

$$
A=0.00151 P^{0.8757},
$$

where $A$ is the area in square miles, and $P$ is the total city population. Assuming each town to be circular in shape allows one to calculate a radius from the estimated area.

This study was supported by National Science Foundation grant GS-1082. The data were assembled by G. Aspbury; M. Landman and F. Rens performed the programming and required computations in conjunction with the University of Michigan Computing Center. 


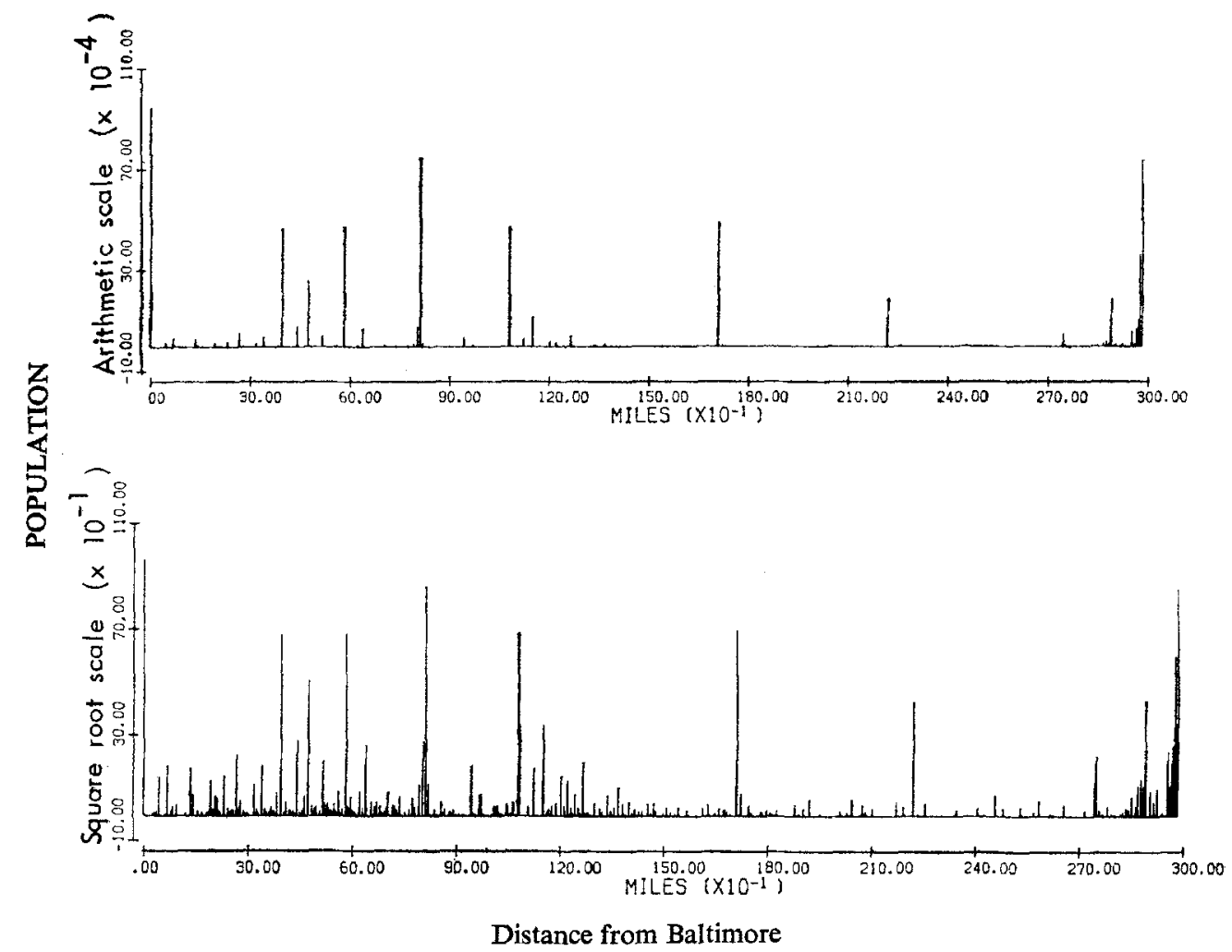

Figure 1. City Size Versus Distance from Baltimore

Invoking further assumptions regarding the distribution of population within the towns permits calculation of an instantaneous population density, which is then used as the signal to be analyzed. Four such models have been calculated: a "cylindrical" town (uniform density); a "conical" town (uniform decline in density); a "parabolic" town (parabolic decline in density from the center, with zero population and zero decline at the edge of the town); and a "cosinusoidal" town (with density slope of zero at the center and edge). Given the estimated radius, the instantaneous and central densities are calculated by requiring that the total population in each case be equal to that of the actual town, Table 1. Some representative values are given in Table 2. The models chosen do not depart appreciably from the more frequently proposed exponential decay (6) or Gaussian models (13) of city densities but have the advantage of greater simplicity for calculation purposes. Each of the foregoing models was employed to produce an estimated population density signal at increments of one mile from Baltimore to San Francisco, Figure 2.

The results of the spectral density calculations (11) are shown in Figures 3 and 4. It is seen that the spectra resulting from the four models of population density 
TABLE 1

$P=$ Total population of the city,

$R=$ Radius of the city, $R=0.0219 P^{0.44}$ (miles),

$X=$ Distance from center of the city, in miles, $0 \leq X \leq R$,

$D=$ Instantaneous population density, persons per square mile, and

$\pi=3.14 \ldots$.

$\begin{array}{ll}\text { Cylindrical Model: } & D=\frac{P}{\pi R^{2}} . \\ \text { Conical Model: } & D=\frac{3 P}{\pi R^{2}}-\frac{3 P X}{\pi R^{3}} . \\ \text { Parabolic Model: } & D=\frac{6 P}{\pi R^{4}}(X-R)^{2} . \\ \text { Cosine Model: } & D=\frac{\pi P}{R^{2}\left(\pi^{2}-4\right)}\left[1-\cos \left(\frac{\pi X}{R}\right)\right] .\end{array}$

Central densities can be estimated by setting $X \equiv 0 . \quad$ In each of the above models, the densities are obtained by requiring that

$$
P=2 \pi \int_{0}^{R} D d x
$$

TABLE 2

\begin{tabular}{c|c|c|c|c|c}
\hline \multirow{2}{*}{ City Population } & \multirow{2}{*}{ Radius* } & \multicolumn{4}{|c}{ Central Density ${ }^{\dagger}$} \\
\cline { 2 - 6 } & & Cylindrical & Conical & Parabolic & Cosine \\
\hline $1,000,000$ & 9.56 & 3,483 & 10,449 & 20,898 & 11,713 \\
500,000 & 7.05 & 3,205 & 9,615 & 19,230 & 10,779 \\
100,000 & 3.47 & 2,642 & 7,927 & 15,853 & 8,886 \\
50,000 & 2.56 & 2,431 & 7,294 & 14,588 & 8,176 \\
10,000 & 1.26 & 2,004 & 6,013 & 12,026 & 6,740 \\
5,000 & 0.93 & 1,844 & 5,533 & 11,066 & 6,202 \\
1,000 & 0.46 & 1,520 & 4,561 & 9,122 & 5,113 \\
\hline
\end{tabular}

* Theoretical radius in miles calculated using Nordbeck's formula, radius $=0.0219 P^{0.44}$.

$\dagger$ Persons per square mile according to the several models.

have very similar shapes. All are low frequency spectra and have peaks at identical wave numbers. Apparently, the choice of the model is not critical. There does not appear to be appreciable energy (variance) at wave-lengths less than five miles. These results have provided insight for the design of a comparable analysis, now in progress, of the geographically more interesting case in which the two-dimensional distribution of towns is analyzed (14). There do not appear to be any independent analyses of geographical data with which these results are directly comparable, but the general shape conforms to spectra encountered in economics (9). The interest is in the type of process which might have yielded the observed distribution, and, of course, whether central place processes belong to this family. The over-all shape of the 


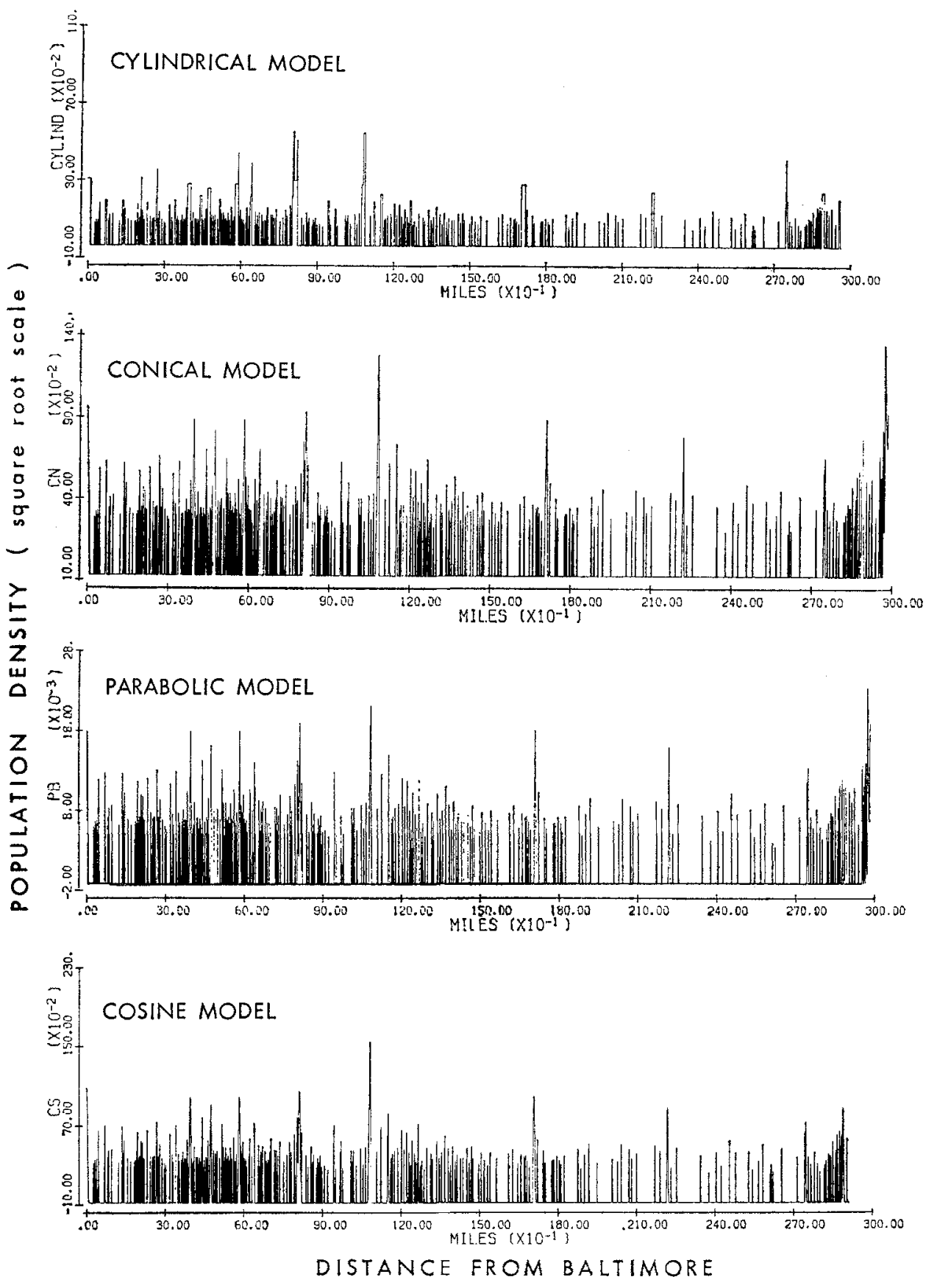

Figure 2. Population Density versus Distance from Baltimore 

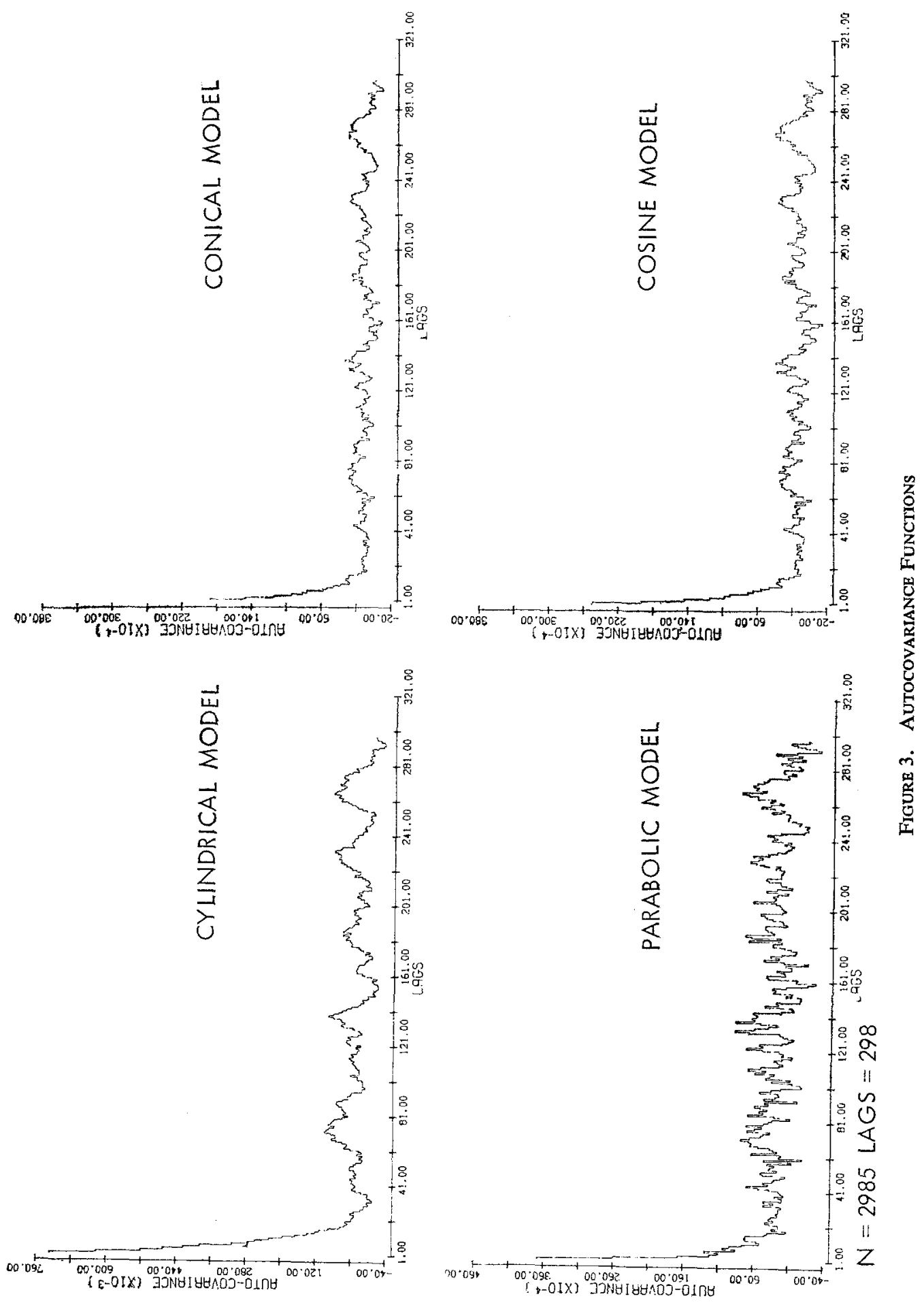

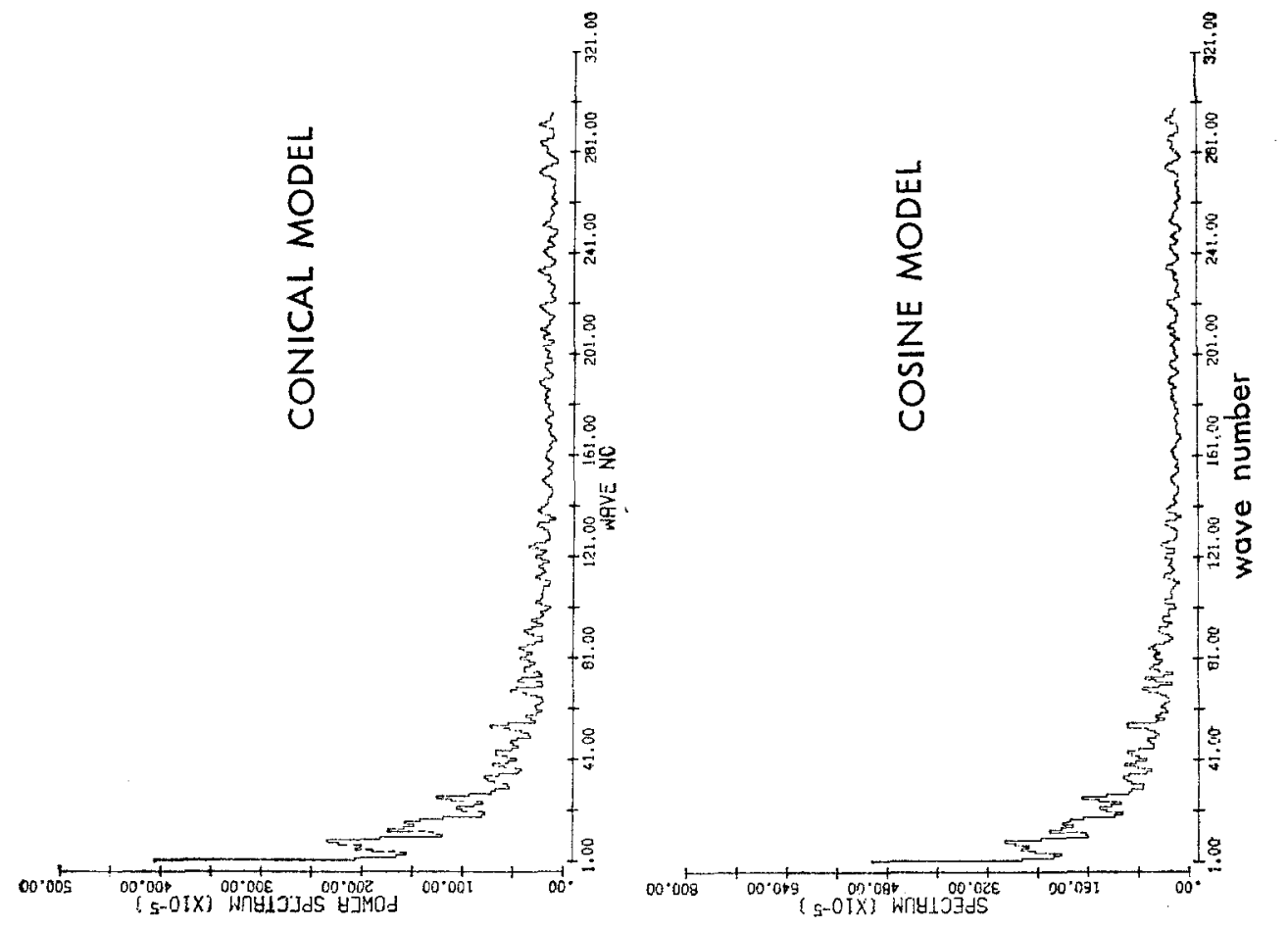

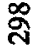

II

讪

ని
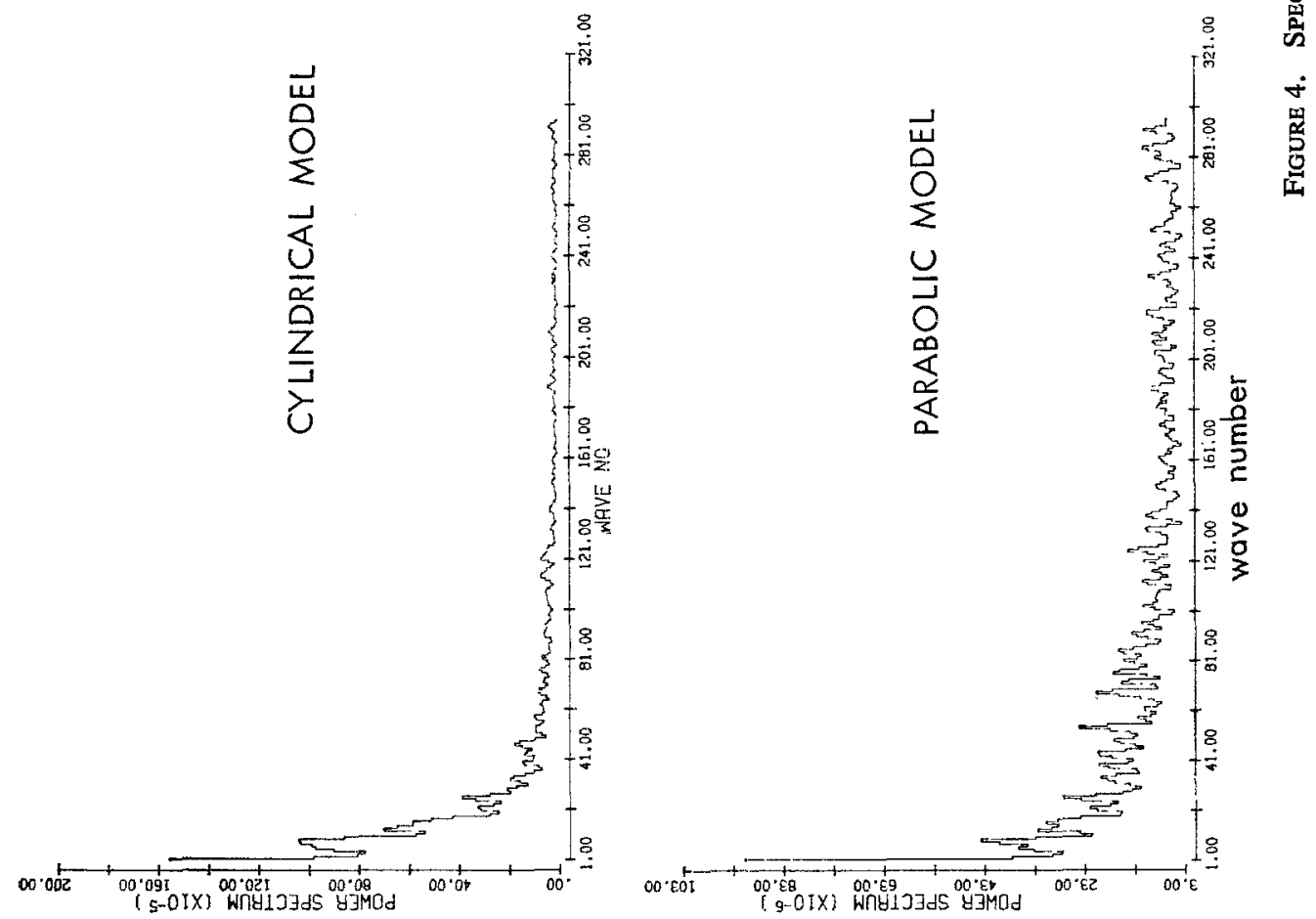


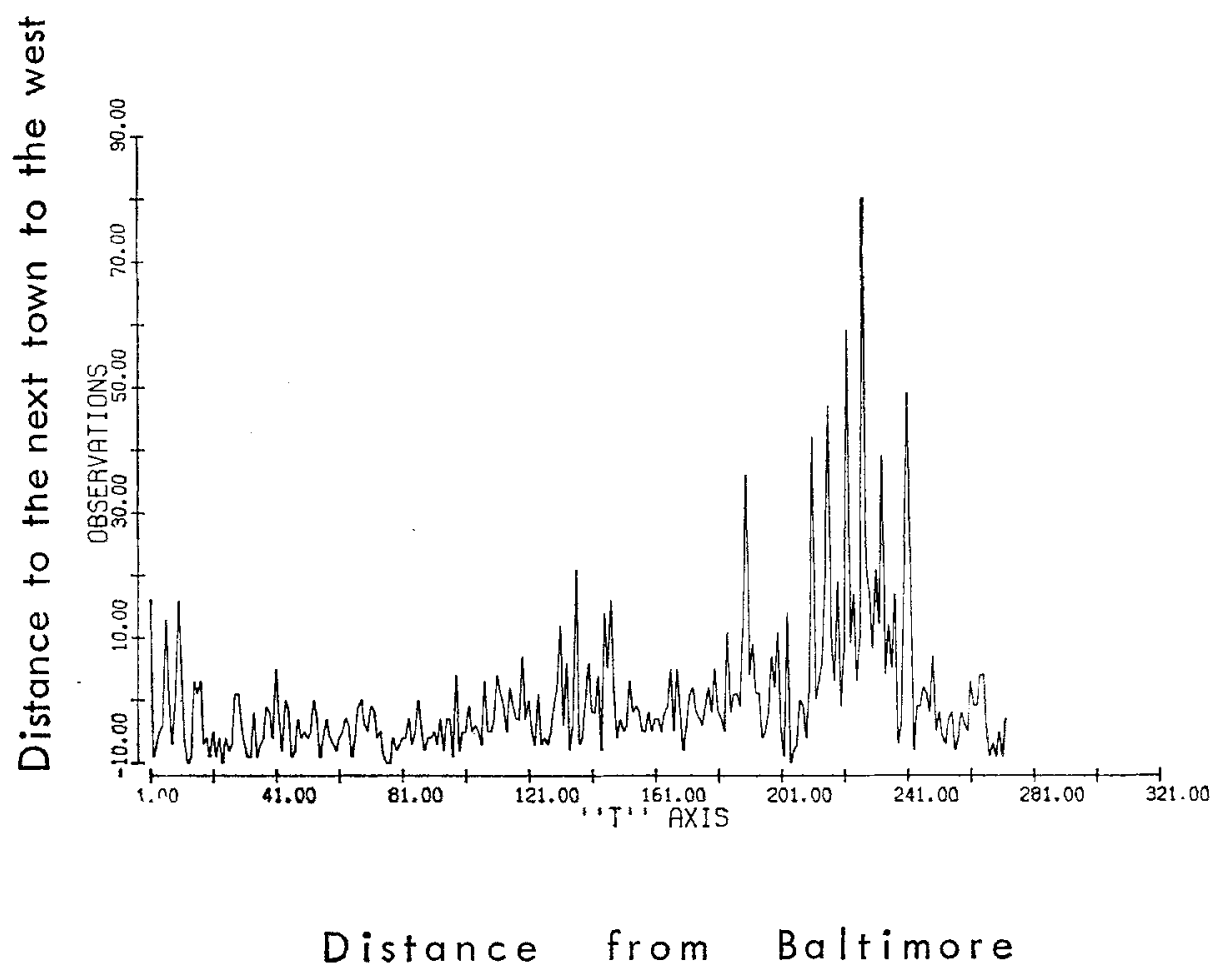

Figure 5. Distance to Adjacent Town (Normalized to Zero Mean)

spectrum suggests an autoregressive model for the processes involved in creating a distribution of towns along U.S. 40 (1). On the assumption that departures from the general trend are important, the analysis, as depicted in Figure 4, suggests spectral peaks at wave-lengths of approximately eleven, twenty-three to twenty-seven, thirtyseven to forty-six, and of sixty-six to seventy-five miles, corresponding, of course, to the distribution of four size classes of towns along the highway. These values are nearly harmonics of eleven miles, but the peaks are significant only at the 10 per cent level, using a Chi-square test, and this interpretation must be considered tentative. The hypothesis of stationarity is difficult to justify from geographical theory, but separate calculations for the eastern and western halves of the data did not result in appreciably different spectra. The geographical spread functions, used to obtain the continuous density signal from the discrete city spacing, each operate as local convolutions on the data, providing a further complication. The distance between towns, shown in Figure 5 as a function of distance from Baltimore, averages about ten miles, with a variance of the same size, which clearly suggests a Poisson process. Taken together, these results suggest a Markov process plus a weak cyclical component. This is the statistical interpretation. A substantive translation might be approximately that set- 
tlements along the highway are initially essentially random, but that central place competition then provides a tendency toward spatial organization, and this is reflected in the spatial pattern. This interpretive model, obviously an oversimplification, then has implications for an analysis of different historical stages in the evolution of highway settlement.

\section{REFERENCES}

1. Agterberg, F. “Computer Techniques in Geology," Earth Science Reviews, III (1967), pp. 4777.

2. Bartlett, M. S. "The Spectral Analysis of Two-Dimensional Point Processes," Biometrika, No. 51, III (1964), pp. 299-311.

3. Bendat, J. S. and A. G. Piersol. Measurement and Analysis of Random Data. New York: John Wiley \& Sons, Inc., 1966.

4. Blackman, R. and J. Tukey. The Measurement of Power Spectra. New York: Dover Publications, Inc., 1959.

5. Christaller, W. Central Places in Southern Germany, Baskin translation. Englewood Cliffs. New Jersey: Prentice Hall, Inc., 1966.

6. Clark, C. "Urban Population Densities," Journal of the Royal Statistical Society, B, CXIV (1951), pp. 490-496.

7. Dacey, M. F. "The Geometry of Central Place Theory," Geografiska Annaler, B. No. 2, XLVII (1965), pp. 111-124.

8. Epstein, E. S. and J. A. Leese. "Application of Two-Dimensional Spectral Analysis to the Quantification of Satellite Cloud Photographs," Journal of Applied Meteorology, II (1963), pp. 629-644.

9. Granger, C. "The Typical Spectral Shape of an Economic Variable," Econometrica, No. 1, XXXIV (1966), pp. 150-161.

10. Jenkins, G. M. and D. G. Watts. Spectral Analysis and its Applications. San Francisco: Holden-Day, 1968.

11. Karreman, H.F. "Computer Programs for Spectral Analysis of Economic Time Series," Research Memorandum No. 59, Econometric Research Program, Princeton University, July, 1963.

12. Nordbeck, S. "The Law of Allometric Growth," Michigan Inter-University Community of Mathematical Geographers, Paper No. 7, 1965, p. 16. (Available through University Microfilms as OP-33067.)

13. Sherrat, G. G. "A Model for General Urban Growth," Management Sciences: Models and Techniques, II (1960), pp. 147-159.

14. Tobler, W. R. "Spectral Analysis of Spatial Series," Proceedings, Fourth Annual Conference on Urban Planning Information Systems and Programs, University of California, Berkeley, 1966, pp. 179-186. 